\title{
The effect of augmented reality versus traditional advertising: a comparison between neurophysiological and self-reported measures
}

\author{
Rumen Pozharliev ${ }^{1}$ (D) Matteo De Angelis ${ }^{1} \cdot$ Dario Rossi $^{1}$
}

Accepted: 27 April 2021 / Published online: 10 May 2021

(C) The Author(s) 2021

\begin{abstract}
Despite the growing application of augmented reality in advertising, there is limited understanding about how customers respond to their interaction with the augmented reality advertising and how it differs from a standard paper-based advertising. Augmented reality ads are immersive, interactive, and lifelike, which means they may help companies create an emotional connection with their customers. The authors test if customers would respond in terms of emotional and affective intensity differently to augmented reality versus standard paper-based advertising. The results of two laboratory studies that consider physiological measures of arousal (galvanic skin response), self-reported measure of affect intensity and willingness to pay show that the higher willingness to pay for customers exposed to augmented reality as opposed to standard paper-based ads is driven by the physiological arousal, but not by the self-reported affect intensity and that processing fluency possibly underlies consumer's enhanced emotional responses toward AR. These results suggest that replacing traditional advertisements with augmented reality advertisements enhances customer physiological responses and willingness to pay, with possible implications on customer segmentation and marketing communication.
\end{abstract}

Keywords Augmented advertising · Physiological arousal · Self-reported affect intensity $\cdot$ Willingness to pay $\cdot$ Processing fluency

Rumen Pozharliev

rpozharliev@luiss.it

Matteo De Angelis

mdeangelis@luiss.it

Dario Rossi

drossi@luiss.it

1 LUISS Guido Carli University, Viale Romania, 32, 00197 Rome, Italy 


\section{Introduction}

The market for augmented reality (hereafter, AR), which can be defined as the integration of digitally created media within an existing real environment (Azuma et al., 2001), is projected to increase from roughly 5.91 billion in 2018 to more than 198 billion in 2025 (Statista, 2019). Companies around the world have been increasingly using AR as an advertising tool to showcase their products and services in retail stores. Examples of AR applications that might simplify consumers' decision-making are Ikea Place, which enables customers to place the company's furniture wherever they imagine it in their homes (Joseph, 2017), and Lacoste LCST AR, which allows customers to virtually try on shoes (Arthur, 2014).

The past literature on advertising suggests that ad-induced arousal strongly influences consumers' intention to buy the products shown in the ad (Sanbonmatsu \& Kardes, 1988; Singh \& Churchill Jr, 1987). However, measuring arousal and its impact on customers' behavioral intentions is a major challenge for research in interactive advertising (Belanche et al., 2017; Pozharliev et al., 2017). Specifically, past empirical evidence on AR applications in marketing communication indicates that AR advertising can enhance different aspects of consumers' affective responses (Poushneh \& Vasquez-Parraga, 2017; Yim et al., 2017). However, previous studies on emotions elicited by consumer experience with AR advertising typically relied solely on retrospective self-reported measures, and hence reported representations of emotions rather than emotions themselves, which in turn may lead to missing important relationships between emotions, advertising type, and purchase outcomes (Jessen et al., 2020; Park \& Yoo, 2020; Poncin \& Mimoun, 2014; van Esch et al., 2019). Consumer neuroscience methods offer more direct access to the unconscious emotional process that affect customer responses to advertising (Dmochowski et al., 2014; Falk et al., 2012; Venkatraman et al., 2015) and thus may help us uncover relationships that other methods would miss. Specifically, we expect neurophysiological, but not self-reported, measures of emotion to mediate the relationship between advertising-type AR (versus traditional) and purchase outcomes. Therefore, the main objective of this paper is to study whether retrospective self-reported measure of arousal versus real-time physiological measure of arousal differ in their prediction regarding the behavioral intentions for a product advertised through AR (versus print advertisement). This question is of critical importance for companies that are looking to assess the impact of AR advertising on consumer emotions and whether these emotions drive WTP for the product shown in the ad.

The present research offers two major contributions to advancing extant scientific knowledge. First, we contribute to the literature on consumers' responses to AR. In particular, while previous work has investigated issues such as the impact of responsiveness and playfulness of AR on attitude toward a product (Park \& Yoo, 2020), the effect of discomfort with AR on attitude toward the brand (van Esch et al., 2019), or the influence of customer engagement with AR on anticipated satisfaction (Jessen et al., 2020), our research investigates the 
intensity of consumers' emotional responses as a possible mediator of the impact of AR (versus print) advertising on consumers' behavioral intentions. Moreover, building on the processing fluency model, we show that AR (versus print) advertising enhances the ease with which consumers process product-related information, which in turn leads to consumers having more positive emotional responses toward the product/brand. In doing so, we identify a novel theoretical mechanism-processing fluency-underlying consumers' enhanced emotional responses toward AR advertising (Lee \& Labroo, 2004).

Second, we contribute to the growing body of literature that seeks to understand how unconscious emotional processes affect online experiences and customer responses to advertising (Dmochowski et al., 2014; Falk et al., 2012; Venkatraman et al., 2015). This stream suggests that neurophysiological measures of emotions can predict future consumer behavior above and beyond traditional self-reported metrics (Berns \& Moore, 2012; Boksem \& Smidts, 2015; Pozharliev et al., 2015). On this basis, we introduce the idea that a neurophysiological measure of emotionsnamely physiological arousal—can potentially offer unique information on consumers' behavioral intentions for a product experienced through AR, which would be unobtainable with self-reported measures. In particular, we use consumer neuroscience (namely, galvanic skin response; hereafter, GSR) measures to examine whether the underlying physiological arousal (versus the self-reported affect intensity) will drive customer willingness to pay (hereafter, WTP) for a product advertised through AR versus print advertising. In doing so, our research helps clarify the methodological strengths of neurophysiological measures for research in interactive advertising. Specifically, our results show that neurophysiological measures of emotions provide a better way of capturing consumers' responses to AR compared to self-reported measures.

Our research might also offer practical implications for marketing communication managers and retailers looking for new ways to emotionally engage customers, and particularly for those managers interested in empirical evidence supporting their decision to invest in AR. Specifically, we show that companies that are looking to leverage AR should use physiological arousal to measure the impact of AR advertising on customer behavioral intention for the product(s) shown in the ad.

One key finding is that neurophysiological measures can be more effective in unveiling the dynamic nature of emotions and their impact on consumer intentions toward products experienced through AR advertising (Berns \& Moore, 2012; Boksem \& Smidts, 2015).

\section{Conceptual development}

\subsection{AR in extant marketing and communication research}

Recent studies on AR suggest that the combination of virtual and real environments, which is a peculiar characteristic of AR technology, is capable of providing unique sensory experiences (Yang et al., 2020). Unlike traditional 2D advertising, AR advertisements allow the viewer to live a more interactive, lifelike experience, which 
increases processing fluency (Lee \& Labroo, 2004) and possibly leads to more favorable attitudes and behavioral responses (Hilken et al., 2017). Indeed, AR allows customers to actively engage with products and services-for example, by virtually placing an IKEA desk in a real-time view of their living room, which might increase the ease of making the purchase decision.

Even though recent industry reports suggest that investments in AR will continue to grow, there are some concerns about the actual impact of these augmented technologies on customer experience. In particular, there is uncertainty about the effect of AR-based benefits (emotional and affective) on customer decision-making (Javornik, 2016) and the unconscious processes that can affect the impact of AR on consumer behavior (Dmochowski et al., 2014; Venkatraman et al., 2015). Thus, marketing scholars and managers might need a more in-depth understanding of consumers' emotional and affective responses in response to AR experiences and how these responses impact behavioral intentions.

\subsection{Self-reported arousal and advertising outcomes}

What little in-depth analysis there is on marketing and communication research on AR has focused on customer acceptance modeling (Huang \& Liao, 2015). Only recently have researchers started recognizing the potential of AR to enhance customer emotional responses (Tsai et al., 2020). For example, recent research suggests that AR is able to provide customers with a compelling experience (Yang et al., 2020), in line with the idea that AR could produce positive affective responses and enhance customer satisfaction (Poncin \& Mimoun, 2014).

We extend the literature on customers' affective responses to AR by focusing on the role of arousal, an emotional mechanism able to explain behavioral intentions toward products advertised through AR. From a psychological perspective, arousal represents (1) a state of wakefulness or excitement (Shapiro \& MacInnis, 2002); (2) activation, alertness, or energization (Kroeber-Riel, 1979); and (3) an elevated state of bodily function (Singh \& Churchill Jr, 1987). For our purposes, arousal is conceptualized as the intensity of the emotional response to affect-laden stimuli such as an advertisement (Moore \& Harris, 1996). The affect intensity measurement (AIM) scale measures the strength with which individuals experience their emotions in response to emotion-eliciting stimuli, and as such, it represents an appropriate tool for evaluating consumers' state of excitement in relation to AR (Moore \& Harris, 1996).

Marketers commonly seek to increase the intensity of emotional responses in their efforts to attract consumers (Lang, 1990). In advertising research, ad-induced arousal is found to moderate the effectiveness of the advertising messages (Sanbonmatsu \& Kardes, 1988; Singh \& Churchill Jr, 1987). Specifically, Storbeck and Clore (2008) suggest that advertising can facilitate consumers' association of products with certain sources of arousal, leading consumers to feel more excited about the product shown in the ad. Previous research has also shown that AR can enhance different aspects of consumers' affective responses, such as product attitude (Park \& Yoo, 2020), brand attitude (van Esch et al., 2019), and store satisfaction (Poncin \& Mimoun, 2014). What all these 
studies have in common is that they primarily rely on self-reported measures of emotions, which are susceptible to several types of measurement errors (see Venkatraman et al., 2015 for more details). First, retrospective self-reported measures do not allow for real-time measurement of arousal (Robinson \& Clore, 2001): thinking about how you felt in the past does not necessarily reflect how you really felt at that time; likewise, consumers may not accurately recall experienced emotions (Pizzi et al., 2015). Secondly, self-reported measures of arousal can be biased due to several reasons, including peoples' unwillingness to share their true emotions, social conformity, or overly positive responses (Podsakoff, 2003; Poels \& Dewitte, 2006).

Therefore, while it is reasonable to predict that AR advertising should lead to higher WTP for a product compared to print advertising, it is possible that selfreported measures of arousal might mask the emergence of such an effect. Thus, the question empirically investigated in this research is: Will self-reported affective intensity drive higher WTP for a product when consumers are exposed to AR (versus traditional) advertising?

\subsection{Customer physiological arousal and advertising}

Both the psychophysiological nature of arousal and its frequent use in advertising suggest that the effectiveness of interactive advertising depends on marketers' ability to stimulate users' arousal. In contrast to retrospective measures of arousal, neurophysiological metrics allow for the measurement of both automatic and subconscious emotional responses in real time (Boksem \& Smidts, 2015; Pozharliev et al., 2017; Vecchiato et al., 2010). Thus, neurophysiological measures of arousal could enrich the overall understanding of consumer emotional experience with AR advertising and help companies better predict the impact of these emotions on customer intentions toward products experienced through AR.

From a physiological perspective, arousal represents an enhancement of the physiological activity that reflects the degree of activation or alertness (Singh \& Churchill Jr, 1987). A well-known measure of psychophysiological reactions to marketing stimuli is the GSR (Vecchiato et al., 2010). This method is based on the analysis of subtle changes in the galvanic skin responses related to the activation of the autonomic nervous system (ANS), a dual system composed of the sympathetic and parasympathetic systems that reflect the "internal" emotional state of a person. Emotional intensity can be obtained by measuring the GSR, generated by the sympathetic autonomic activation of the sweat glands in the skin, which can be easily measured from the palm of a hand. In particular, an increase in GSR is an indicator of an increase in sweating in response to an arousing emotional stimulus. In advertising research, there are few measurements of GSR; some studies, while testing other emotional measures or using other neurophysiological methods, have used the GSR as a validation tool (Vecchiato et al., 2010). These studies suggest that GSR reflects a conscious expectancy of an outcome and/or non-conscious emotional intensity (e.g., arousal) that drives future decision-making (Reimann et al., 2012). Hence, GSR activity is a valid measure for studying the intensity of consumer emotional response to advertising stimuli (Ohme et al., 2011). GSR, moreover, is 
a measure that may allow marketers to record instantaneous and subconscious emotional responses that could help them better predict their ads' impact on consumer behavioral intentions.

Drawing on these empirical insights, we hypothesize that, compared to traditional advertising, AR advertising produces higher physiological arousal (GSR), which in turn results in customers expressing higher WTP for the advertised product.

\section{Study 1: AR versus traditional advertising}

\subsection{Participants, variables, and methods}

Sixty participants, encompassing students and staff from a mid-size European University $\left(M_{\text {age }}=24.6, \mathrm{SD}=4.8 ; 50 \%\right.$ females $)$, took part in a laboratory study. After signing the informed consent, participants were randomly assigned to one of the two experimental conditions: the AR advertising condition versus traditional advertising condition. In both conditions, the participants were exposed to the advertisements using an iPhone 6S. The three furniture products from the IKEA catalogue (Fig. 1) were presented in a randomized order.

In the traditional advertising condition, each product was shown as a page of a catalogue on the smartphone screen, while in the AR advertising condition, each product was presented through the IKEA Place application. Prior to the AR advertising condition, relevant participants received instructions on how to use the application for the purposes of the study. After completing the task, participants assessed

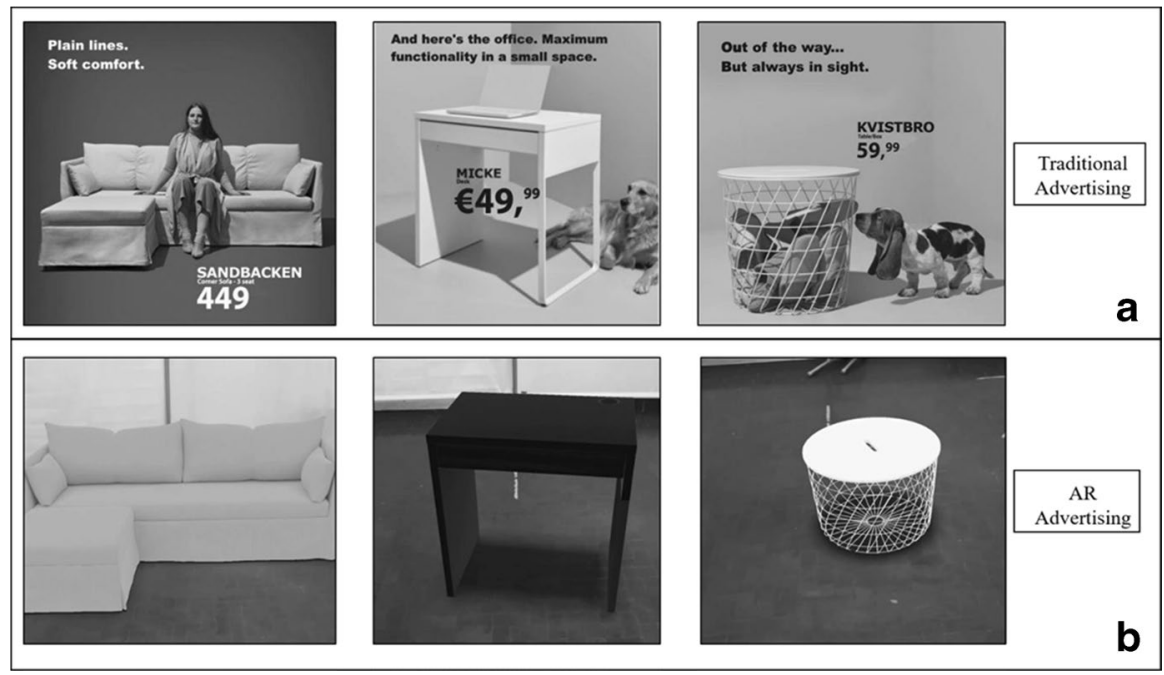

Fig. 1 Stimuli used in the study in the two experimental conditions. a Traditional communication and b AR communication. Furniture products, respectively, from left to right: SANDBACKEN sofa, MICKE desk, and KVISTBRO basket 
the affect intensity using a five-item questionnaire (Moore \& Harris, 1996): "While exposed to the advertisement, how strongly did you feel? 1-emotional, 2-happy, 3-moved, 4-joyous, 5-delightful." Items were rated on a seven-point Likert scale, with "weak/strong" as endpoints.

Next, participants were asked to indicate their WTP (Cameron \& James, 1987) for the three pieces of IKEA furniture ("How much would you like to pay for this product?") using numeric open answer in a constant sum. For each product, we calculated the $Z$-score among the participants since the three furniture pieces had three different price ranges, in order to be able to average the three obtained values and derive a summary measure of WTP that could take all three products into account.

Moreover, in both conditions, we recorded the GSR of the participants with a sampling rate of $32 \mathrm{~Hz}$. Two electrodes for the GSR recording were attached to the palmar side of the middle phalanges of the second and third fingers of the respondent's non-dominant hand by means of a Velcro fastener. Each respondent was asked to hold the smartphone and look at the home screen for $1 \mathrm{~min}$ without interacting, in order to obtain a subjective baseline for the GSR signal. GSR recording continued through the entire experimental session. The participants in the traditional advertising condition sat in a comfortable chair and saw, in a randomized order, the three pictures of the furniture products on the smartphone screen. After each picture, we collected their WTP for the respective product.

Through the IKEA Place application, the participants in the AR advertising condition interacted with the three furniture pieces in a randomized order. Participants were instructed to access the application on the smartphone. At this time, participants were free to navigate through the available space in the real world, to manipulate virtual objects and to place them on the location they preferred. After each interaction, we collected their WTP for the respective product. We used LEDAlab software to obtain the tonic component of the skin conductance, which was used as a measure of respondents' arousal level (Benedek \& Kaernbach, 2010). The same approach was used to obtain measures for both the baseline and the interaction with the advertisings. In order to have a comparable index among participants, we calculated the Z-score of the GSR during the interaction task using the mean and standard deviation obtained during baseline. We controlled for respondents' previous experience with $\mathrm{AR}$, as this factor may influence customer responses to AR advertising.

\subsection{Results}

\subsubsection{Main effects}

The results of the independent sample $t$-test showed that participants in the AR advertising condition (coded as 1) showed higher reported affect intensity $\left(M_{\mathrm{AR}}=5.28, \mathrm{SD}=1.09\right.$ versus $M_{\text {traditional }}=3.45, \mathrm{SD}=1.39 ; t(58)=5.66, p<0.001$; Cohen's $d=1.19$ ) and higher levels of GSR than those in the traditional advertising condition (coded as 0$)\left(M_{\mathrm{AR}}=9.75, \mathrm{SD}=9.1\right.$ versus $M_{\text {traditional }}=2.63, \mathrm{SD}=3.24$; $t(58)=-4.0, p<0.001$; Cohen's $d=0.92)$, while no significant differences between the two conditions emerged when taking into account participants' WTP $(p=0.4)$. 
We performed an independent sample $t$-test on affective intensity, GSR, and WTP to see if the previous use of AR could affect participants' conscious and unconscious responses. The participants showed no difference in affective intensity $(p=0.93)$, GSR $(p=0.76)$, and WTP $(p=0.31)$ in relation to their previous use of AR technology. Thus, participants' responses were not affected by their past experience with AR.

\subsubsection{Mediation effects}

Next, we investigated whether the type of advertising affected participants' WTP through self-reported affect intensity and GSR, respectively, using the Monte Carlo method implemented in the SPSS macro Process (model 4, Fig. 2) (Hayes, 2017). In the first step of the analysis, we regressed self-reported affect intensity and GSR on the binary independent variable (i.e., type of advertising), showing an increase of affect intensity $\left(R^{2}=0.36 ; F(1,58)=31.99 ; p<0.001 ; f^{2}=0.56\right.$; $b=1.83 ; t=5.66, p<0.001)$ and GSR $\left(R^{2}=0.22 ; F(1,58)=16.07 ; p<0.001\right.$; $\left.f^{2}=0.28 ; b=7.12 ; t=4.01, p<0.001\right)$ in the AR advertising condition. Then, we regressed WTP on affect intensity, GSR, and the independent variable $\left(R^{2}=0.16\right.$; $\left.F(3,56)=3.43 ; p=0.02 ; f^{2}=0.19 ;\right)$; the results revealed a significant, positive effect $\left(f_{\text {partial }}^{2}=0.15\right)$ of GSR $(b=0.03 ; t=3.05, p<0.004)$ but a non-significant effect of affect intensity $(p=0.59)$ and the independent variable $(p=0.42)$. Importantly, the results indicated the presence of a positive indirect effect of the independent variable on WTP through GSR $(b=0.23 ; 95 \%$ C.I.: $=0.06,0.45)$, which signals that GSR acted as a mediator of the effect of advertising type on WTP. In contrast, the indirect effect of the independent variable on WTP through selfreported affect intensity was not significant $(b=0.06,95 \%$ C.I. $=-0.15,0.3)$, suggesting that this measure did not play any mediational role.

Our results provide an answer to our research question by showing that the higher self-reported affect intensity for AR (versus traditional) advertising does not lead to a higher WTP for the advertised product. Moreover, our results provide support for our hypothesis, suggesting that physiological measures of arousal, but not self-reported measures of affect intensity, might act as a significant predictor of consumers' WTP for products advertised through AR (versus print advertising).

Fig. 2 Conceptual model for the study

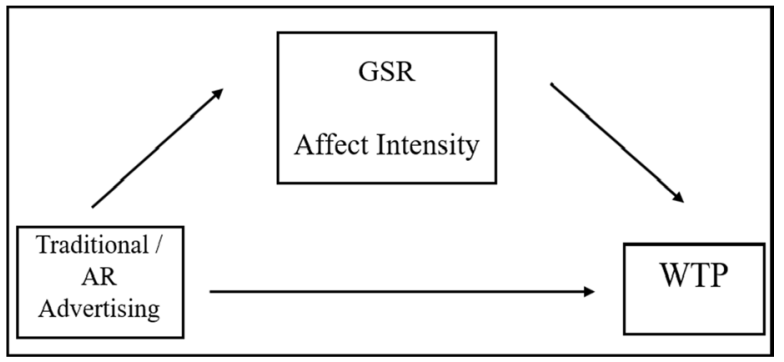




\section{Study 2: AR versus active traditional advertising (enhanced processing fluency)}

According to the processing fluency model, advertising exposures enhances the ease with which consumers process product/brand-related information; this increased fluency leads to consumers having more favorable responses toward the product/brand. Although the effect of processing fluency on affective responses is well-documented (Lee \& Labroo, 2004; Reber et al., 1998), there are no previous studies that examine whether the ability of AR (versus print) advertising to enhance consumers' emotional responses is driven by the medium's superior conceptual and/or perceptual fluency. Thus, the objective of study 2 is to examine the role that processing fluency plays in enhancing consumer emotional responses to AR advertising.

\subsection{Participants, variables, and methods}

Fifty participants, recruited from a mid-size European University $\left(M_{\text {age }}=24.70\right.$, $\mathrm{SD}=4.02 ; 56 \%$ females), took part in a laboratory study. After signing the informed consent, participants were randomly assigned to one of the two experimental conditions: the AR advertising condition versus the active traditional advertising condition. In this study, we modified the traditional advertising condition by making it more active: Specifically, we asked participants to write a prompt imagining where and how they would organize the piece of furniture in a room of their house/apartment "Imagine and describe where and how you would organize this couch in a room of your house/apartment." In both conditions, the participants were exposed to the advertising using an iPhone $\mathrm{X}$. The furniture products from the IKEA catalogue, already used in study 1 , were presented in a randomized order.

In the active traditional advertising condition, each product was shown as a page of a catalogue on the smartphone screen, while in the AR advertising condition, each product was presented through the IKEA Place application. Like in study 1, all participants involved in the AR advertising condition received instructions on how to use the application for the purposes of the study. After completing the task, we assessed participants' self-reported arousal using a five-item questionnaire (Wirtz et al., 2000): "Please rate your emotions according to the way this product advertising made you feel: Relaxed/Stimulated, Calm, Excited, Sluggish/Frenzied, Dull/Jittery, Sleepy/Wide Awake, Unaroused/Aroused." Items were rated on a seven-point semantic differential scale.

Then, participants were asked to indicate their WTB (Sweeney et al., 1999) for the two pieces of IKEA furniture using a three-item questionnaire ("There is a strong likelihood that I will buy the product I just saw," "I would consider buying the product I just saw," "I will purchase the table bin I just saw"), rated on a sevenpoint Likert scale with "strongly disagree/strongly agree" as endpoints.

Next, in order to check for the participants' level of processing fluency (Graf et al., 2018) for the presented products in the two experimental conditions, we used a five-item questionnaire ("After watching this product communication, the process of studying the advertising product was Incomprehensible/Comprehensible, 
Unclear/Clear, Difficult/Easy, Disfluent/Fluent, Effortful/Effortless") that was rated on a seven-point semantic differential scale. Finally, like in study 1 , we recorded all participants' GSR throughout the study.

\subsection{Results}

\subsubsection{Manipulation check}

The results of the independent sample $t$-test on processing fluency showed no significant differences, indicating that the participants in the two experimental condition processed the product advertising in the same way $(p=0.73)$.

\subsubsection{Main effects}

The results of the independent sample $t$-test showed that participants in the AR advertising condition (coded as 1$)$ showed higher reported arousal $\left(M_{\mathrm{AR}}=4.37\right.$, $\mathrm{SD}=0.95$ versus $M_{\text {active_traditional }}=3.75, \mathrm{SD}=0.85 ; t(48)=-2.45, p=0.02$; Cohen's $d=0.65)$ and higher levels of GSR than those in the traditional advertising condition (coded as 0$)\left(M_{\mathrm{AR}}=19.84, \mathrm{SD}=17.25\right.$ versus $M_{\text {active_traditional }}=6.79, \mathrm{SD}=7.49$; $t(48)=-3.42, \quad p=0.001$; Cohen's $d=0.88$ ), while no significant differences emerged between the two conditions when taking into account participants' WTB $(p=0.91)$.

\subsubsection{Mediation effects}

We investigated whether the type of advertising affected participants' WTB through both self-reported arousal and GSR using the SPSS macro Process (model 4) (Hayes, 2017). In the first step of the analysis, we regressed self-reported arousal and GSR on the binary independent variable, which produced an increase of both arousal $\left(R^{2}=0.11 ; F(1,48)=9.94 ; p=0.02 ; f^{2}=0.12 ; b=0.62 ; t=2.43, p=0.02\right)$ and GSR $\left(R^{2}=0.20 ; F(1,48)=11.67 ; p=0.001 ; f^{2}=0.25 ; b=13.04 ; t=3.42\right.$, $p=0.001$ ) in the AR advertising condition. Then, we regressed WTB on arousal, GSR, and the independent variable, but no significant effect emerged-not even an indirect effect $\left(R^{2}=0.06 ; F(3,56)=3.43 ; p=0.41\right)$. The lack of an indirect effect between the GSR and WTB can be explained by the presence of a more active traditional advertising as an experimental condition. We elaborate on the results of study 2 in the discussion.

\section{Discussion}

This research has shown that the higher WTP for consumers exposed to AR (as opposed to standard print advertising) is driven by consumers' physiological arousal, but not by their self-reported affect intensity. Overall, we believe these results might offer relevant theoretical and managerial insights, as well as generate 
questions about customers' emotional responses to AR advertising that future studies might address.

\subsection{Theoretical implications}

Our research advances extant research on consumer responses to AR in two important ways: (1) by providing insights on the emotional processes induced by AR advertising vis-à-vis traditional advertising and on the influence of these processes on consumers' WTP for the advertised products; and (2) by comparing retrospective self-reported measure of arousal with real-time physiological arousal on their ability to significantly predict consumers' WTP toward products shown through AR (versus traditional) advertising.

One of the main challenges for research in interactive advertising is the difficulty of measuring arousal and its impact on customers' behavioral intentions (Belanche et al., 2017). One key finding that emerges from our study is that neurophysiological measures can be more effective in unveiling the dynamic nature of emotions and their impact on consumer intentions toward products experienced through AR advertising (Berns \& Moore, 2012; Boksem \& Smidts, 2015). Importantly, and in line with previous research on affective responses to AR (Park \& Yoo, 2020; Poncin \& Mimoun, 2014; van Esch et al., 2019), we did find higher self-reported affect intensity for AR (versus traditional) advertising. However, this enhanced self-reported affect intensity did not predict the WTP for the advertised product. A plausible explanation, in line with the peak-end rule, is that customers are only able to recall their general level of arousal (e.g., based on averaged representation about arousal rather than on arousal itself) or tend to only remember and report the moments of intense arousal (Kahneman \& Krueger, 2006). Another plausible explanation is provided by the well-known recency effect, which assumes that the last outcome of a sequence of experiences should be the most prevalent in the evaluation process (Anderson, 2000). In such cases, the self-reported affect intensity cannot capture the dynamic information included in the second-by-second variation of emotional experience, and thus, it is significantly reduced in its ability to predict consumer intentions.

Second, there is an ongoing debate among marketing scholars about how consumer neuroscience methods and measures can add value to traditional advertising research (Lee et al., 2018). Some studies show that consumer neuroscience methods and measures add value by complementing or validating traditional marketing research measures on a neurophysiological level (Falk et al., 2012), while others suggest that consumer neuroscience can add value by predicting customer behavior above and beyond traditional marketing measures (Pozharliev et al., 2015; Venkatraman et al., 2015). Our results provide empirical evidence for the latter by showing that AR (versus print) advertising produces higher physiological arousal, which in turn drives higher WTP for the product shown in the ad. As such, our findings show that customers' physiological arousal is able to predict consumers' behavior intentions above and beyond self-reported marketing measures. 
Third, our results provide a theoretical argument for the enhanced emotional response to AR (versus print) advertising. Specifically, AR advertising enhances the processing fluency, defined as the ease with which consumers process productrelated information, which is positively valenced (Reber et al., 1998). According to this theory, when consumers are presented with a brand/product that is easy to process, the positive experience of fluent processing underlies their more favorable affective and emotional responses to the brand/product (Lee \& Labroo, 2004). In doing so, we identify a novel theoretical mechanism underlying consumers' enhanced effective and emotional responses toward AR advertising.

\subsection{Managerial implications}

Our research can offer relevant insights to marketing managers interested in understanding how to effectively use AR as well as print advertising in their communication strategies. First, our study clearly indicates that managers should use a mixed set of market research tools to investigate consumer emotional responses to communication and retailing strategies. Specifically, our results show that physiological (compared to self-reported) arousal is able to improve predictions of consumer behavioral intentions toward products advertised through AR. This finding suggests that managers who are seeking to leverage the potential of AR should use consumer neuroscience and measure physiological arousal to better assess the impact of AR advertising on the WTP the product shown in the ad (Berns \& Moore, 2012; Boksem \& Smidts, 2015).

Secondly, our results suggest that AR advertising might work not only for products that are novel but also for traditional products, such as those employed in our experiment. This suggests that it is the AR technology that fosters customers' emotional responses and positive behavioral intentions. By extension, managers could not only increase the amount of AR used in advertising but also possibly raise the price of products advertised through AR.

Finally, our research suggests that advertising managers can potentially make their traditional (i.e., print) advertising more effective by increasing its fluency and personal connection to consumers. This could be done, for instance, by using digital tools (i.e., QR codes) that allow consumers to be more active in their interaction with the ad, making their purchase decision easier.

\section{Limitations and future research}

The limitations of our work can serve as ideas for future research. First, our findings are limited to one particular digital platform, namely Ikea Place, where most of the products that customers see are much bigger than their viewing screen size (e.g., bed, table, sofa). It would be interesting to see if our results are confirmed with small-sized products (e.g., watches, diamond rings). After all, using AR to present those products may generate more realistic product visualization and thus affect 
customers' physiological responses to the digital platform and/or the advertised product or service (Yim et al., 2017).

Second, our unconscious measures of customer experience with AR are limited to individual physiological responses (GSR). GSR allows us to understand the impact of arousal and emotional intensity in the relationship between AR and purchase outcomes, but it does not allow us to assess more nuanced emotional responses. The application of other consumer neuroscience methods and metrics could produce further insights into the affective, cognitive, and social processes that affect customers' responses to and behavior with AR-based technologies. For example, a combination of GSR and heart rate variability (HRV) will allow us to assess both the intensity and valance of the emotional responses to AR-based technologies. The electroencephalography (EEG) method offers another neurophysiological approach to assess the valance of the emotional responses to ARbased advertising. For example, Vecchiato et al. (2010) found greater left (versus right) frontal brain activity for commercials that consumers particularly liked (versus disliked). Thus, the use of EEG frontal asymmetry, in combination with GSR and HRV, could provide further relevant insights into customers' emotional responses and the unconscious drivers of behavioral intentions with AR-based technologies.

Third, our findings are limited to one particular product category, namely home furniture (e.g., bed, table, sofa). Future research could, therefore, compare how emotional responses toward AR advertising might differentiate across different products and how this is tied to consumer behavior. Specifically, previous research suggests that the relative level and influence of affective responses (e.g., pleasure and arousal) to a product differ significantly, depending on whether the product is hedonic or functional in nature. Specifically, felt arousal during the product experience is higher for the hedonic product than for the functional product, and emotional responses were significant drivers of consumers' behavioral intentions toward said product (Kempf, 1999).

Finally, the active traditional advertising condition asked participants to write a prompt imagining where and how they would organize the piece of furniture in a room of their house/apartment. Previous research suggests that mental simulation is important for harnessing one's imagination (Taylor et al., 1998). Specifically, mental simulation plays a key role in problem solving and emotion regulation because it enables consumers to envision possibilities and develop plans for bringing those possibilities about (Taylor et al., 1998). Therefore, future research could look at the role of mental simulation in problem solving and/or emotional responses to ARbased advertising. For example, one could formulate the imagination instructions as a mental simulation by identifying a specific goal, such as one relating to the décor or comfort, and the steps needed to achieve this goal. Moreover, future work could provide further theoretical convergence to our findings. For example, scholars could study the competitive value of fluency in AR (versus traditional) advertising and whether there is anything traditional advertising can do to "catch up" with AR (Reber et al., 1998). 
Author contribution All authors contributed to the study conception and design. Material preparation, data collection, and analysis were performed by Dario Rossi and Rumen Pozharliev. The first draft of the manuscript was written by Rumen Pozharliev, and all authors commented on previous versions of the manuscript. All authors read and approved the final manuscript.

Funding Open access funding provided by Luiss University within the CRUI-CARE Agreement.

Data availability The dataset is available upon request to the corresponding author.

Code availability Not applicable.

\section{Declarations}

Conflict of interest The authors declare no competing interests.

Open Access This article is licensed under a Creative Commons Attribution 4.0 International License, which permits use, sharing, adaptation, distribution and reproduction in any medium or format, as long as you give appropriate credit to the original author(s) and the source, provide a link to the Creative Commons licence, and indicate if changes were made. The images or other third party material in this article are included in the article's Creative Commons licence, unless indicated otherwise in a credit line to the material. If material is not included in the article's Creative Commons licence and your intended use is not permitted by statutory regulation or exceeds the permitted use, you will need to obtain permission directly from the copyright holder. To view a copy of this licence, visit http://creativecommons.org/licen ses/by/4.0/.

\section{References}

Anderson, J. R. (2000). Learning and memory: An integrated approach. Wiley.

Arthur, R. (2014). Lacoste launches virtual try-on app for new LCST Line. https://thecurrentdaily.com/ 2014/07/31/lacoste-launches-virtual-try-on-app-for-new-lcst-line/. Accessed 3 May 2020.

Azuma, R., Baillot, Y., Behringer, R., Feiner, S., Julier, S., \& MacIntyre, B. (2001). Recent advances in augmented reality. IEEE Computer Graphics Applications, 21, 34-47.

Belanche, D., Flavián, C., \& Pérez-Rueda, A. (2017). Understanding interactive online advertising: Congruence and product involvement in highly and lowly arousing, skippable video ads. Journal of Interactive Marketing, 37, 75-88.

Benedek, M., \& Kaernbach, C. (2010). A continuous measure of phasic electrodermal activity. Journal of Neuroscience Methods, 190, 80-91.

Berns, G. S., \& Moore, S. E. (2012). A neural predictor of cultural popularity. Journal of Consumer Psychology, 22(1), 154-160.

Boksem, M. A., \& Smidts, A. (2015). Brain responses to movie trailers predict individual preferences for movies and their population-wide commercial success. Journal of Marketing Research, 52(4), $482-492$.

Cameron, T. A., \& James, M. D. (1987). Estimating willingness to pay from survey data: An alternative pre-test-market evaluation procedure. Journal of Marketing Research, 24, 389-395.

Dmochowski, J. P., Bezdek, M. A., Abelson, B. P., Johnson, J. S., Schumacher, E. H., \& Parra, L. C. (2014). Audience preferences are predicted by temporal reliability of neural processing. Nature Communications, 5, 1-9.

Falk, E. B., Berkman, E. T., \& Lieberman, M. D. (2012). From neural responses to population behavior: Neural focus group predicts population-level media effects. Psychological Science, 23, 439-445.

Graf, L. K., Mayer, S., \& Landwehr, J. R. (2018). Measuring processing fluency: One versus five items. Journal of Consumer Psychology, 28(3), 393-411.

Hayes, A. F. (2017). Introduction to mediation, moderation, and conditional process analysis: A regression-based approach. Guilford Publications. 
Hilken, T., de Ruyter, K., Chylinski, M., Mahr, D., \& Keeling, D. I. (2017). Augmenting the eye of the beholder: Exploring the strategic potential of augmented reality to enhance online service experiences. Journal of the Academy of Marketing Science, 45, 884-905.

Huang, T. L., \& Liao, S. (2015). A model of acceptance of augmented-reality interactive technology: The moderating role of cognitive innovativeness. Electronic Commerce Research, 15, 269-295.

Javornik, A. (2016). Augmented reality: Research agenda for studying the impact of its media characteristics on consumer behaviour. Journal of Retailing Consumer Services, 30, 252-261.

Jessen, A., Hilken, T., Chylinski, M., Mahr, D., Heller, J., Keeling, D. I., \& de Ruyter, K. (2020). The playground effect: How augmented reality drives creative customer engagement. Journal of Business Research, 116, 85-98.

Joseph, S. (2017). How Ikea is using augmented reality. https://digiday.com/marketing/ikea-using-augme nted-reality/. Accessde 3 May 2020.

Kahneman, D., \& Krueger, A. B. (2006). Developments in the measurement of subjective well-being. Journal of Econonomic Perspectives, 20, 3-24.

Kempf, D. S. (1999). Attitude formation from product trial: Distinct roles of cognition and affect for hedonic and functional products. Psychology \& Marketing, 16(1), 35-50.

Kroeber-Riel, W. (1979). Activation research: Psychobiological approaches in consumer research. Journal of Consumer Research, 5, 240-250.

Lang, A. (1990). Involuntary attention and physiological arousal evoked by structural features and emotional content in TV commercials. Communication Research, 17, 275-299.

Lee, A. Y., \& Labroo, A. A. (2004). The effect of conceptual and perceptual fluency on brand evaluation. Journal of Marketing Research, 41(2), 151-165.

Lee, N., Chamberlain, L., \& Brandes, L. (2018). Welcome to the jungle! The neuromarketing literature through the eyes of a newcomer. European Journal of Marketing, 52(1/2), 4-38.

Moore, D. J., \& Harris, W. D. (1996). Affect intensity and the consumer's attitude toward high impact emotional advertising appeals. Journal of Advertising, 25, 37-50.

Ohme, R., Matukin, M., \& Pacula-Lesniak, B. (2011). Biometric measures for interactive advertising research. Journal of Interactive Advertising, 11, 60-72.

Park, M., \& Yoo, J. (2020). Effects of perceived interactivity of augmented reality on consumer responses: A mental imagery perspective. Journal of Retailing Consumer Services, 52, 101912.

Pizzi, G., Marzocchi, G. L., Orsingher, C., \& Zammit, A. (2015). The temporal construal of customer satisfaction. Journal of Service Research, 18, 484-497.

Podsakoff, N. P. (2003). Common method biases in behavioral research: A critical review of the literature and recommended remedies. Journal of Applied Psychology, 885(879), 10-1037.

Poels, K., \& Dewitte, S. (2006). How to capture the heart? Reviewing 20 years of emotion measurement in advertising. Journal of Advertising Research, 46(1), 18-37.

Poncin, I., \& Mimoun, M. S. B. (2014). The impact of "e-atmospherics" on physical stores. Journal of Retailing Consumer Services, 21, 851-859.

Poushneh, A., \& Vasquez-Parraga, A. Z. (2017). Discernible impact of augmented reality on retail customer's experience, satisfaction and willingness to buy. Journal of Retailing Consumer Services, 34, 229-234.

Pozharliev, R., Verbeke, W. J., \& Bagozzi, R. P. (2017). Social consumer neuroscience: Neurophysiological measures of advertising effectiveness in a social context. Journal of Advertising, 46, 351-362.

Pozharliev, R., Verbeke, W. J., Van Strien, J. W., \& Bagozzi, R. P. (2015). Merely being with you increases my attention to luxury products: Using EEG to understand consumers' emotional experience with luxury branded products. Journal of Marketing Research, 52, 546-558.

Reber, R., Winkielman, P., \& Schwarz, N. (1998). Effects of perceptual fluency on affective judgments. Psychological Science, 9(1), 45-48.

Reimann, M., Castaño, R., Zaichkowsky, J., \& Bechara, A. (2012). How we relate to brands: Psychological and neurophysiological insights into consumer-brand relationships. Journal of Consumer Psychology, 22, 128-142.

Robinson, M. D., \& Clore, G. L. (2001). Simulation, scenarios, and emotional appraisal: Testing the convergence of real and imagined reactions to emotional stimuli. Personality and Social Psychology Bulletin, 27, 1520-1532.

Sanbonmatsu, D. M., \& Kardes, F. R. (1988). The effects of physiological arousal on information processing and persuasion. Journal of Consumer Research, 15, 379-385.

Shapiro, S., \& MacInnis, D. J. (2002). Understanding program-induced mood effects: Decoupling arousal from valence. Journal of Advertising, 31, 15-26. 
Singh, S. N., \& Churchill, G. A., Jr. (1987). Arousal and advertising effectiveness. Journal of Advertising, 16(1), 4-40.

Statista (2019). Augmented reality market size worldwide 2017-2025. https:/www.statista.com/statistics/ 897587/world-augmented-reality-market-value/. Accessed 10 May 2020.

Storbeck, J., \& Clore, G. L. (2008). Affective arousal as information: How affective arousal influences judgments, learning, and memory. Social Personality Psychology Compass, 2, 1824-1843.

Sweeney, J. C., Soutar, G. N., \& Johnson, L. W. (1999). The role of perceived risk in the quality-value relationship: A study in a retail environment. Journal of Retailing, 75(1), 77-105.

Taylor, S. E., Pham, L. B., Rivkin, I. D., \& Armor, D. A. (1998). Harnessing the imagination: Mental simulation, self-regulation, and coping. American Psychologist, 53(4), 429.

Tsai, W. H. S., Tian, S. C., Chuan, C. H., \& Li, C. (2020). Inspection or Play? A study of how augmented reality technology can be utilized in advertising. Journal of Interactive Advertising, 20(3), 244-257.

van Esch, P., Arli, D., Gheshlaghi, M. H., Andonopoulos, V., von der Heidt, T., \& Northey, G. (2019). Anthropomorphism and augmented reality in the retail environment. Journal of Retailing Consumer Services, 49, 35-42.

Vecchiato, G., Astolfi, L., Fallani, F. D. V., Cincotti, F., Mattia, D., Salinari, S., Soranzo, R., \& Babiloni, F. (2010). Changes in brain activity during the observation of TV commercials by using EEG GSR and HR measurements. Brain Topography, 23(2), 165-179.

Venkatraman, V., Dimoka, A., Pavlou, P. A., Vo, K., Hampton, W., Bollinger, B., Hershfield, H. E., \& Winer, R. S. (2015). Predicting advertising success beyond traditional measures: New insights from neurophysiological methods and market response modeling. Journal of Marketing Research, 52(4), 436-452.

Wirtz, J., Mattila, A. S., \& Tan, R. L. (2000). The moderating role of target-arousal on the impact of affect on satisfaction-An examination in the context of service experiences. Journal of Retailing, 76(3), 347-365.

Yang, S., Carlson, J. R., \& Chen, S. (2020). How augmented reality affects advertising effectiveness: The mediating effects of curiosity and attention toward the ad. Journal of Retailing Consumer Services, 54, 102020.

Yim, M. Y. C., Chu, S. C., \& Sauer, P. L. (2017). Is augmented reality technology an effective tool for e-commerce? An interactivity and vividness perspective. Journal of Interactive Marketing, 39, 89-103.

Publisher's note Springer Nature remains neutral with regard to jurisdictional claims in published maps and institutional affiliations. 